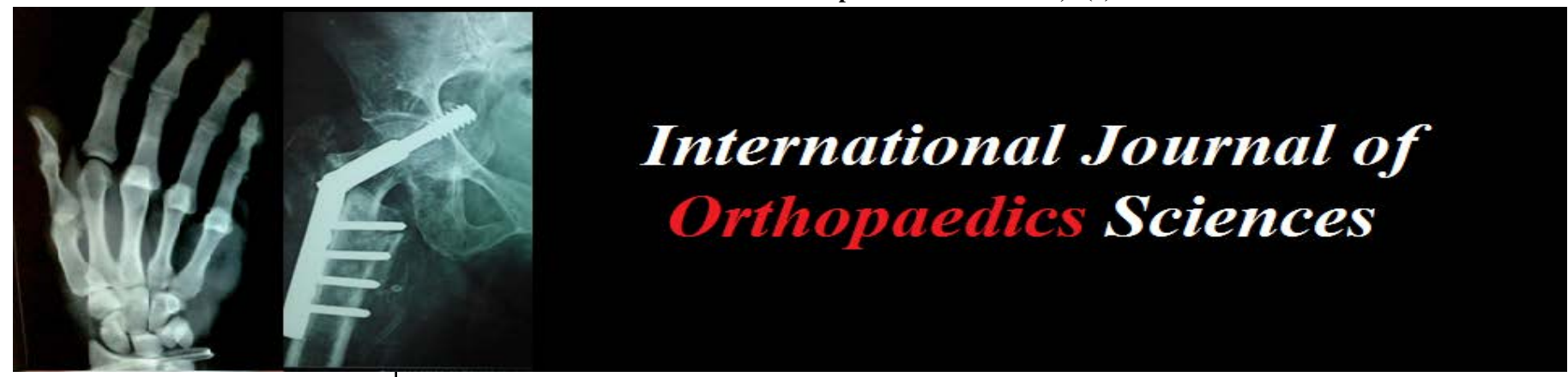

E-ISSN: 2395-1958

P-ISSN: 2706-6630

IJOS 2021; 7(3): 650-654

(C) 2021 IJOS

www.orthopaper.com

Received: 07-05-2021

Accepted: 09-06-2021

Dr. Gompa Parameswara Rao Associate Professor,

Department of Orthopedics, Anil Neerukonda Hospital,

Sangivalasa, Vishakhapatnam, Andhra Pradesh, India

Dr. MD Qamar Abdul Azeez

Associate Professor,

Department of Orthopedics,

Anil Neerukonda Hospital,

Sangivalasa, Vishakhapatnam,

Andhra Pradesh, India

Dr. Raviteja Kunadharaju

Assistant Professor,

Department of Orthopedics,

Anil Neerukonda Hospital,

Sangivalasa, Vishakhapatnam,

Andhra Pradesh, India

Dr. Manchiraju VS Sudhakar Postgraduate Resident,

Department of Orthopedics,

Anil Neerukonda Hospital,

Sangivalasa, Vishakhapatnam,

Andhra Pradesh, India

\section{Prospective study of clinico radiological outcome of distal end clavicle fractures treated with hook plate}

\author{
Dr. Gompa Parameswara Rao, Dr. MD Qamar Abdul Azeez, Dr. Raviteja \\ Kunadharaju and Dr. Manchiraju VS Sudhakar
}

DOI: https://doi.org/10.22271/ortho.2021.v7.i3j.2815

\section{Abstract}

Background \& Objectives: Clavicle fracture is the commonest fracture amongst adults and roughly a quarter of all clavicle fractures occur at the lateral end ${ }^{[1]}$. These fractures are unstable due to the various deforming forces which act on the fragments as well as the small distal fracture fragment. At most times the deforming forces are not taken into consideration, and the fracture is not fixed securely. In this study, we assessed a fixation technique using the lateral end clavicle hook plates to find out whether it provided a stable fixation with good functional outcome.

Methods: This study is a prospective, hospital based study conducted in Anil Neerukonda Hospital and NRI Institute of Medical Sciences, Visakhpatnam, between May 2018 to May 2021. The fractures were classified according to Neer's classification and were followed up at regular intervals. In total, 12 patients with lateral end clavicle fracture (Neer's Type II) were included in the study. After the informed consent and preoperative investigations were obtained, open reduction and internal fixation was done using a $3.5 \mathrm{~mm}$ lateral end clavicular hook plate under regional anesthesia. Postoperative $\mathrm{X}$-rays were done on day 1 and every 6 weeks after operation, until radiological union was achieved. The postoperative pain was assessed using Visual Analogue Scale (VAS) on postoperative days 1, 2 and 10. Postoperatively arm pouch sling was given for 10 days followed by active mobilization. Patients were asked to do their daily routine work and avoid lifting heavy weights. The functional outcome was assessed at the end of 2nd and 6th months with the help of Disabilities of the Arm, Shoulder and Hand (DASH) scoring.

Results: There were no intraoperative complications in the procedure. The mean VAS score on postoperative day 1 was found to be 5 which decreased to 3 on day 2 and 0 on day 10 . The mean DASH score was calculated as 10.58 at the end of postoperative month 2 and then 4.2 at the end of month 6 . There was one case of superficial infection which was resolved with local debridement, there was initial restriction of overhead abduction in this case but was not painful and was managed conservatively.

Conclusion: Lateral end clavicular hook plate is a good fixation system for lateral end clavicle fractures. Operative time is reduced and surgical dissection is minimum. Device provides good angular stability and helps in early mobilization. It may well be the answer to the fixation questions of the lateral clavicle fractures, although larger comparative studies between the surgical treatment methods are required to confirm the same.

Keywords: lateral end clavicle fracture, hook plate, Ac joint subluxation, fracture stability, functional outcome

\section{Introduction}

Clavicle fracture is the commonest fracture amongst adults and roughly a quarter of all clavicle fractures occur at the lateral end ${ }^{[1]}$. The latter was classified according to the relationship of the fracture line to the Coracoclavicular (CC) ligaments and the extension into the Acromioclavicular (AC) joint. Type I fractures occur lateral to the CC ligaments, and are usually stable. In type II the fracture line occurs medial to the CC ligaments resulting in displacement of the medial fragment. Type III are intra-articular fractures involving the AC joint, the majority are not displaced ${ }^{[2]}$. These fractures are unstable due to the various deforming forces which act on the fragments as well as the small distal fracture fragment. At most times the deforming forces are not taken into consideration, and the fracture is not fixed securely.

\section{Dr. MD Qamar Abdul Azeez} Associate Professor, Department of Orthopedics, Anil Neerukonda Hospital, Sangivalasa, Vishakhapatnam, Andhra Pradesh, India 
Many treatment modalities have been used for the management of such fractures. Nonoperative methods are associated with high rates of nonunion (22\%-50\%) ${ }^{[3-5]}$ out of which $14 \%$ cases [6] were symptomatic. Many operative treatment modalities have been tried for the management of lateral clavicle fracture including coracoclavicular screws ${ }^{[6-8]}$ Kirschner wires [9] tension bands ${ }^{[10-12]}$ hook plates [13, 14] nonlocked ${ }^{[15]}$ and locked plates $[14,16-20]$ The operative modalities are not without complications. These include nonunited and malunited fractures, pin migration, impingement of the plate, bleeding, the requirement of removal of the plate ${ }^{[16,}$ 18] in all the fixation modalities. In this study, we have evaluated the functional and radiological outcomes of the patients in whom clavilcular hook plate was used for fixation of the lateral end of clavicle fractures.

Table 1: Table shows in number of patients and union time and constant score at final follow up complication

\begin{tabular}{|c|c|c|c|c|c|}
\hline Study & $\begin{array}{c}\text { No of } \\
\text { Patients }\end{array}$ & Union time & $\begin{array}{c}\text { Union } \\
\text { rate }\end{array}$ & $\begin{array}{c}\text { Constant score at } \\
\text { final follow up }\end{array}$ & Complications \\
\hline $\begin{array}{c}\text { Meda } \text { et al. (2006) } \\
\text { [28] }\end{array}$ & 31 & 12 weeks (6-18) & $100 \%$ & $92(84-100)$ & $\begin{array}{c}\text { 2 cases superficial infection, 6 } \\
\text { impingement, 5 osteolysis }\end{array}$ \\
\hline Tiern et al. (2012) ${ }^{[29]}$ & 28 & -- & $96 \%$ & 97 & 9 impingement, 7 osteolysis, one nonunion \\
\hline $\begin{array}{c}\text { Good et al. (2012) } \\
\text { [30] }\end{array}$ & 36 & 12 week (8-16) & $95 \%$ & $83.8(44-100)$ & $\begin{array}{c}2 \text { fracture clavicle at medial edge of plate, } \\
\text { one nonunion }\end{array}$ \\
\hline Current study (2017) & 12 & 8.7 weeks (6-12) & $100 \%$ & 94 (84-100) & 1 superficial infection.No Impingement. \\
\hline
\end{tabular}

Table 2: Inclusion Criteria

\begin{tabular}{|c|c|}
\hline 1 & Age -20 to 45 years \\
\hline 2 & Fresh fractures $<1$ week \\
\hline 3 & Neer's classification type II a \& II B 3. \\
\hline
\end{tabular}

Table 3: Exclusion Criteria

\begin{tabular}{|c|c|}
\hline 1 & Age $<20$ yrs \\
\hline 2 & Neer's classification type IA \\
\hline 3 & Compound fractures \\
\hline 4 & Associated with neurovascular injury \\
\hline 5 & Associated ipsilateral upper limb fractures \\
\hline
\end{tabular}

\section{Surgical technique}

Patients were positioned in the beach chair position with the affected arm draped free, on an orthopedic radiolucent table, with access for intraoperative radiography.Longitudinal skin incision along the anterior border of the lateral half of the clavicle was used (Figure 1). The deltoid insertion with the periosteum was incised along the skin incision exposing the fracture. The posterior border of the AC joint was identified and the hook of the plate was passed through $5 \mathrm{~mm}$ snip in the trapezium passing under the acromion. The plate was then used to indirectly reduce the medial clavicle into position. Reduction was checked by fluoroscopy and the screws were sequentially inserted from medial to lateral.

Fig 2: Post operative xray

Fig 1: Preoperative xray 
Fig 4: Implants used

Fig 5: Intraoperative image showing provisional stabilization

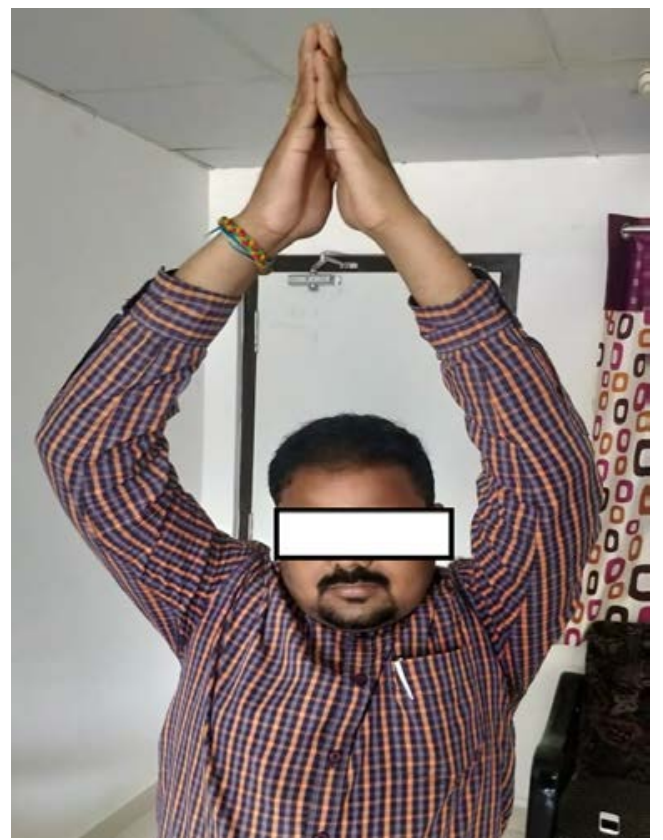

Fig 6: 3 weeks follow up with terminal restriction of abduction, no pain.
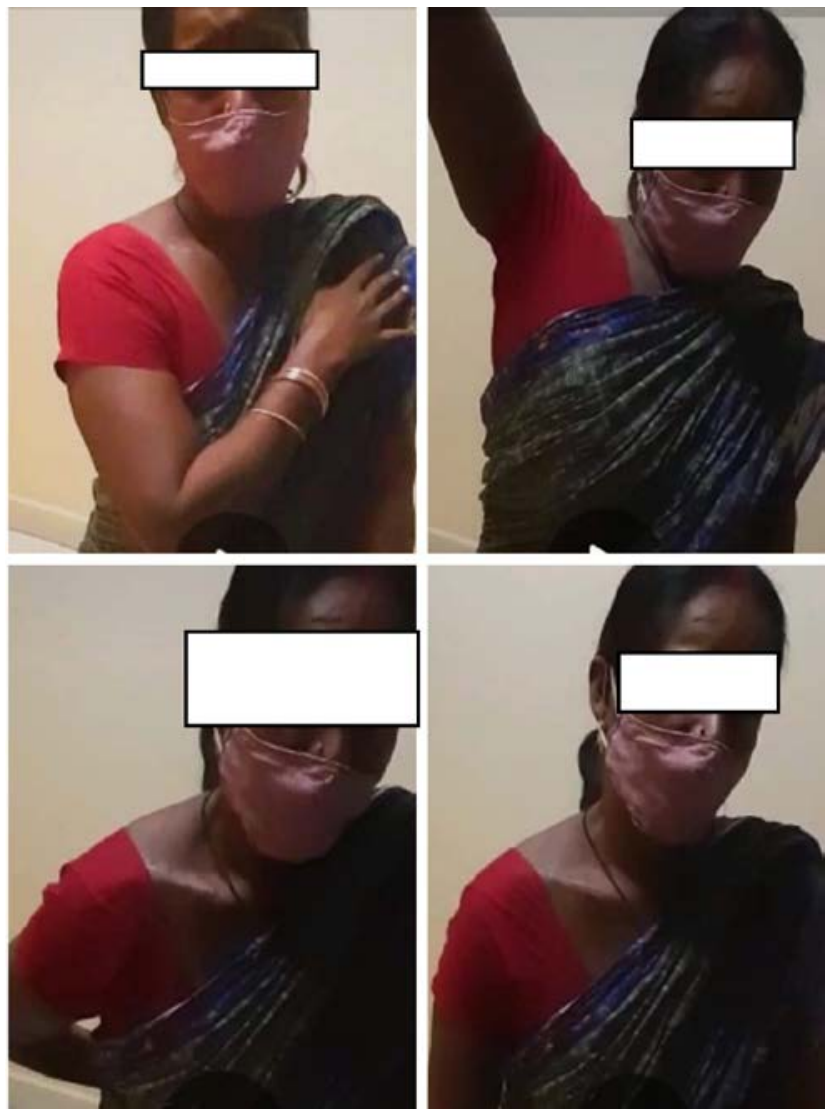

Fig 7: Image with excellent functional outcome and painless ROM.

Post operative care: The shoulder was immobilized in arm sling, and passive and active assisted movements were started as tolerated from day 1.Pendulum exercises were started from day 1 and were advised mobilization of the elbow and wrist. Patients were discharged after 2 days and suture removal done at 10 days. Active shoulder mobilization was started 10 days after the pain subsided and the arm pouch was removed at 2 weeks. X-ray assessment of the clavicle was done on the 1st postoperative day and after every 6 weeks, until radiological union was achieved. The postoperative pain was assessed using Visual Analogue Scale (VAS) on 1st, 2nd, and 10th postoperative day. The analgesics were stopped after 2 days and advised to be taken if the VAS score was more than 4 . The dressing was done on the 2nd day and suture removal on 7th postoperative day. The clinical outcome was assessed on the 2nd and 6th month postoperatively using Disabilities of the Arm, Shoulder and Hand (DASH) scoring system. ${ }^{21}$ The patients were also followed up with the Constant Murley scoring at the second and sixth month postoperatively. The patient was kept in follow up till the bony union was achieved.

\section{Results}

Average age for the patients operated was 28years (21-36yrs). 10 cases were males \& 2 were females. Good reduction was achieved in all the cases. All fractures were closed fractures with no neurovascular defecits.8 cases were Neer's type IIA \& 4 cases were Neer's type IIB. Average time of radiological union was 12- 16 weeks (average time 14.4 weeks). In all 12 patients complete union was achieved. 1 case had superficial surgical site infection which was resolved with local debridement, there was initial restriction of overhead abduction in this case but was not painful and was managed conservatively. 
The mean VAS score on the 1st postoperative day was found to be 5 which decreased to 3 on the 2nd day and 0 on the 10th postoperative day.

The mean DASH score was 11.63, 2 months postoperatively and 4.6 at the end of 6 months. The average Constant Murley scores were 85 at 2 months postoperatively and 94 at 6 months postoperatively. According to the Constant Murley score, the functional outcomes were excellent in 6 patients (50\%), good in 4 (33.3\%), moderate in 2 (16.7\%). None of the plates had to be removed for any implant failures.

\section{Discussion}

Management of the lateral clavicle fractures had been a matter of debate for many decades.

The lateral end clavicle fractures where the distal fracture fragment is small and the deforming forces are great, the nonoperative treatment fails as it is associated with the significant incidence of complications like malunion, nonunion, joint stiffness, etc. The deforming forces are due to the powerful pull of the muscles along with the presence of the coracoacromial ligament and the coracoclavicular ligament and the weight of the arm. They are responsible for the instability of the fracture along with malunion and nonunion, which leads to functional disabilities. Hence, the need for surgical management in the form of stable fixation is necessary in displaced Neer types II and III fractures owing to high non-union rates in conservatively managed fractures. However, there is no consensus about the gold standard fixation techniques. That explain the presence of many fixation methods from $\mathrm{K}$ wires to plates.

The gold standard method in management of unstable fractures, remains anatomical reduction of the fracture and stable fixation to allow early mobilization.Neer and WatsonJones used AC K-wires and reported good results regarding fracture union. However, later reports of complications including hardware failure, breakage, and migration, and prolonged immobilization resulted in poor functional results. Rockwood and Lyon concluded that K-wires is a poor option in management of lateral clavicular fractures ${ }^{[22]}$. Adding tension band to the acromioclavicular wires either metal or sutures, didn't reduce the risk of wire migration and breakage. Hsu et al. compared results of 35 patients fixed by hook plate and 30 patients fixed by transacromial tension band wiring. They reported comparable union time and functional outcome at 6 months in both groups but wires migration and failure in 5 patients of the tension band group. Transacromial fixation is seldom used nowadays because it violates the AC joint with possible subsequent arthritis and prevents the normal AC joint movement resulting in early implant failure. Coracoclavicular screws traditionally used for AC joint dislocations- were used to indirectly reduce and fix unstable distal clavicular fractures. Very few studies have shown good results and few complications [23, 24]. However, the technique didn't gain popularity owing to the potential risks of neurovascular injury or coracoid fractures, and the prolonged immobilization for fear of screw failure. Alternatively, a less rigid coracoclavicular fixation using many types of sutures and bands have gained popularity with comparable good results and less complications. Most of these band fixations could be done arthroscopically ${ }^{[25,26]}$. However coracoid fracture and failure of fixation were reported ${ }^{[26]}$. The clavicular hook plate was designed to allow indirect fixation of the small or comminuted lateral clavicular fragment and at the same time allowing a stable construct that allow union but didn't omit acromioclavicular movements. Stegeman et al, published a meta-analysis of different fixation techniques in treatment of unstable lateral clavicular fractures [27]. There was no significant outcome difference between the clavicular hook plate and the other fixation methods.

In conclusion,lateral end clavicular plates provide adequate stable fixation for the lateral end clavicle fractures and are not associated with any major complications. This low profile implant is easy to use and fits well to the contour of the lateral end of the clavicle. Even with no screw purchase in the small lateral end of the fracture, it provides stable fixation by indirect reduction. It may well be the answer to the fixation woes of the lateral clavicle fractures. Although, larger comparative studies between the various surgical treatment methods are required to confirm the same.

\section{References}

1. Nordqvist A, Petersson C. The incidence of fractures of the clavicle. Clin Orthop Relat Res 1994;300:127-132.

2. Neer CI. Fractures of the distal third of the clavicle. Clin Orthop Relat Res 1968;58:43-50.

3. Nordqvist A, Petersson C, Redlund-Johnell I. The natural course of lateral clavicle fracture. 15 (11-21) year followup of 110 cases. Acta Orthop Scand. 1993;64:87-91.

4. Robinson CM, Court-Brown CM, McQueen MM et al. Estimating the risk of nonunion following nonoperative treatment of a clavicular fracture. J Bone Jt Surg Am. 2004;86:1359-1365.

5. Rokito AS, Zuckerman JD, Shaari JM, et al. A comparison of nonoperative and operative treatment of type II distal clavicle fractures. Bull Hosp Jt Dis. 2002;61:32-39.

6. Ballmer FT, Gerber C. Coracoclavicular screw fixation for unstable fractures of the distal clavicle. A report of five cases. J Bone Jt Surg Br 1991;73:291-294.

7. Macheras G, Kateros KT, Savvidou OD, et al. Coracoclavicular screw fixation for unstable distal clavicle fractures. Orthopedics 2005;28:693-696.

8. Yamaguchi H, Arakawa H, Kobayashi M. Results of the Bosworth method for unstable fractures of the distal clavicle. Int Orthop 1998;22:366-368.

9. Levy O. Simple, minimally invasive surgical technique for treatment of type 2 fractures of the distal clavicle. J Shoulder Elb Surg 2003;12:24-28.

10. Shin SJ, Roh KJ, Kim JO et al. Treatment of unstable distal clavicle fractures using two suture anchors and suture tension bands. Injury 2009;40:1308-1312.

11. Kalamaras M, Cutbush K, Robinson M. A method for internal fixation of unstable distal clavicle fractures: early observations using a new technique. J Shoulder Elb Surg. 2008;17:60-62.

12. Chen $\mathrm{CH}$, Chen WJ, Shih CH. Surgical treatment for distal clavicle fracture with coracoclavicular ligament disruption. J Trauma 2002;52:72-78.

13. Bezer M, Aydin N, Guven O. The treatment of distal clavicle fractures with coracoclavicular ligament disruption: a report of 10 cases. J Orthop Trauma. 2005;19:524-528.

14. Klein SM, Badman BL, Keating CJ, Devinney DS, Frankle MA, Mighell MA. Results of surgical treatment for unstable distal clavicular fractures. J Shoulder Elb Surg http://dx.doi.org/10.1016/j.jse.2009.11.056

15. Haidar SG, Krishnan KM, Deshmukh SC. Hook plate fixation for type II fractures of the lateral end of the clavicle. J Shoulder Elb Surg 2006;15:419-423. 
16. Kona J, Bosse MJ, Staeheli JW, Rosseau RL. Type II distal clavicle fractures: a retrospective review of surgical treatment. J Orthop Trauma 1990;4:115-120.

17. Herrmann S, Schmidmaier G, Greiner S. Stabilisation of vertical unstable distal clavicular fractures (Neer 2b) using locking T-plates and suture anchors. Injury. 2009;40:236-239. http://dx.doi.org/10.1016/j.injury.2008.07.021.

18. Kaipel M, Majewski M, Regazzoni P. Double-plate fixation in lateral clavicle fractures-a new strategy. J Trauma 2010;69:896-900.

19. Oh JH, Kim SH, Lee JH, et al. Treatment of distal clavicle fracture: a systematic review of treatment modalities in 425 fractures. Arch Orthop Trauma Surg 2011;131:525-533. http://dx.doi.org/10.1007/s00402010-1196.

20. Yu C, Sun YH, Zhao CQ et al. Treatment of distal clavicle fracture with distal radius volar locking compression plate. Chin J Traumatol 2009;12:299-301.

21. Anderson K. Evaluation and treatment of distal clavicle fractures. Clin Sports Med 2003;22:319-326.

22. Lyons F, Rockwood C. Migration of pins used on the shoulder. J Bone Joint Surg Am 1990;72:1262-1267.

23. Macheras G, Kateros K, Savvidou O. Coracoclavicular screw fixation for unstable distal clavicle fractures. Orthopaedics 2005;28:693-696.

24. Fazal M, Saksena J, Haddad F. Temporary coracoclavicular screw fixation for displaced distal clavicle fractures. J Orthop Surg 2007;15:9-11.

25. Nourissat G, Kakuda C, Dumontier C, Sautet A, Doursounian L. Arthroscopic stabilization of Neer type 2 fracture of the distal part of the clavicle. Arthroscopy. 2007, 671-674.

26. Cho C-H, Bae K-C, Kim DH. Coracoclavicular Stabilization Using a Suture Button Device for Neer Type IIB Lateral Clavicle Fractures. Arthroscopy: The Journal of Arthroscopic \& Related Surgery 2017;33:5960.

27. Stegeman S, Nacak H, Koen HH, nger B. Surgical treatment of Neer type-2 of the distal clavicle, a metaanalysis. Acta Orthop 2013;84:184-190.

28. Meda P, Machani B, Sinopidis C, Brownson P, SPFrostick. Clavicular hook plate for lateral end fractures: A prospective study. Injury 2006;37:277-283.

29. Tiren D, Bemmel A, Swank D, Linden Fvd. Hook plate fixation of acute displaced lateral clavicle fractures: midterm results and a brief literature overview. J Orthop Surg Res 2012;7:2-1.

30. Good D, Lui D, Leonard M, Morris S, McElwain J. Clavicle hook plate fixation for displaced lateral-third clavicle fractures (Neer type II): a functional outcome study. J Shoulder Elbow Surg 2012;21:1045-1048. 